\title{
Yves Bonnefoy, Rimbaud. Speranza e lucidità
}

\section{Maria Emanuela Raffi}

\section{(2) OpenEdition}

\section{Journals}

\section{Edizione digitale}

URL: http://journals.openedition.org/studifrancesi/6380

DOI: 10.4000/studifrancesi.6380

ISSN: 2427-5856

\section{Editore}

Rosenberg \& Sellier

\section{Edizione cartacea}

Data di pubblicazione: 1 novembre 2010

Paginazione: 576

ISSN: 0039-2944

\section{Notizia bibliografica digitale}

Maria Emanuela Raffi, «Yves Bonnefoy, Rimbaud. Speranza e lucidità», Studi Francesi [Online], 162 (LIV |

III) | 2010, online dal 30 novembre 2015, consultato il 10 janvier 2021. URL: http://

journals.openedition.org/studifrancesi/6380 ; DOI: https://doi.org/10.4000/studifrancesi.6380

Questo documento è stato generato automaticamente il 10 janvier 2021.

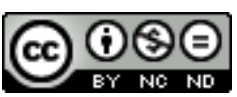

Studi Francesi è distribuita con Licenza Creative Commons Attribuzione - Non commerciale - Non opere derivate 4.0 Internazionale. 
Yves Bonnefoy, Rimbaud. Speranza e lucidità

\author{
Maria Emanuela Raffi
}




\section{NOTIZIA}

YVES BONNEFOY, Rimbaud. Speranza e lucidità, edizione italiana a cura di Fabio sCOTTO, postfazione di Gabriella CARAMORE, Roma, Donzelli, 2010, pp. 300.

Della straordinaria riflessione poetico-critica di Yves Bonnefoy su Rimbaud (Notre besoin de Rimbaud, Seuil, 2009) ha riferito, nella rassegna del n.161 di «Studi francesi», Ida Merello. A distanza di un anno, Fabio sсотто ne propone una interessante versione italiana (traduzioni di Scotto e Caramore), arricchita da un suo saggio introduttivo e dalla postfazione di Gabriella Caramore. Profondo conoscitore dell'opera di Bonnefoy, Fabio Scotto, nella prefazione «Il Rimbaud di Bonnefoy: la lucidità e la speranza», mette nella giusta prospettiva il rapporto con Rimbaud nell'insieme della poetica bonnefoysiana, definendo una "funzione Rimbaud" sottesa a tutto il percorso di scrittura del poeta e fondata sul comune «rifiuto della mistica e del dualismo platonico, quindi di quella che egli [Bonnefoy] chiama l'illusione, o l'inganno della vita eterna post mortem. Sottolineando la grande attenzione filologica che caratterizza questa rivisitazione di Rimbaud, scotto conclude indicando il vibrante appello alla poesia che scaturisce dal testo, la "domanda di senso" che da Rimbaud (e da Baudelaire), attraverso Bonnefoy, non cessa di essere presente.

2 Nella «Postfazione», Gabriella CARAMORE propone un intenso itinerario nell'opera poetica di Bonnefoy e nella sua riflessione sulla poesia, da Mouvement et immobilité de Douve fino a L'Arrière-Pays, recentemente tradotto dalla stessa Caramore, alla ricerca della fondamentale consonanza con Baudelaire e soprattutto con Rimbaud. Segno della presenza e al tempo stesso rivelazione della "più alta assenza", la poesia appare a tutti questi straordinari autori come il luogo privilegiato di «un'introduzione iniziatica dall'assenza alla speranza». 